\title{
Two ways of finding a host: A specialist and a generalist parasitoid species (Hymenoptera: Chalcidoidea: Pteromalidae)
}

\author{
RALPH S. PETERS
}

Zoologisches Forschungsmuseum Alexander Koenig, Adenauerallee 160, 53113 Bonn, Germany; e-mail: r.peters@zfmk.de

Key words. Hymenoptera, Chalcidoidea, Pteromalidae, Nasonia vitripennis, Dibrachys microgastri, parasitic wasps, specialist, generalist, locomotor activity, laboratory experiments, parasitoid life history traits, host finding, olfactory cues

\begin{abstract}
Two closely related parasitoid wasp species with different host specificities were used for experimental studies on the biology of host finding, a crucial element of parasitoid life history: The habitat and host specialist Nasonia vitripennis and the habitat and host generalist Dibrachys microgastri (Chalcidoidea: Pteromalidae). The host finding parameters tested included reaction to olfactory cues, aspects of locomotor activity, ability to locate hidden hosts and day-night-activity. The results revealed distinct interspecific differences that match the respective host and habitat ranges of the two species. In N. vitripennis host finding is dominated by olfactory reaction to hosts and host habitat, i.e., fly puparia and birds' nests. In D. microgastri olfactory cues have only a minor role. Its host finding is characterized by rapid searching at random. Both species are able to locate hidden hosts. Although still incomplete, these insights into host finding by two parasitoid species with different life history strategies indicate they can be characterized by specific combinations of behavioural host finding features.
\end{abstract}

\section{INTRODUCTION}

Host search is a vital component of parasitoid life history (Godfray, 1994). In order to better understand parasitoid biology, host-parasitoid interactions and host-parasitoid communities it is necessary to understand how parasitoids search for hosts. Every parasitoid has evolved a solution to the problem of host finding, which combines suitable behaviour and usage of cues. Theory predicts that parasitoids with different host ranges and specificities display differences at each stage in their search for hosts and in the relative use of olfactory and non-olfactory cues (e.g., Geervliet et al., 2000; Steidle et al., 2003). The most diverse group of parasitoid insects are the parasitic wasps, with more than 50,000 described and over a million estimated species (LaSalle \& Gauld, 1991; Godfray, 1994). To study host finding by parasitoid Hymenoptera, we selected two species with well-known biology in terms of host and habitat range, Nasonia vitripennis (Walker, 1836) and Dibrachys microgastri (Bouché, 1834) (both: Chalcidoidea: Pteromalidae). N. vitripennis is a birds' nest specialist, occasionally occurring in carrion and faeces, and strictly dipterophagous, but able to use a variety of cyclorrhaphous host species (Whiting, 1967; Peters, 2007, 2010a; Peters \& Abraham, 2010). It is frequently used as a model organism in various studies on speciation, developmental genetics and sex allocation (e.g., Gadau et al., 1999; Pultz \& Leaf, 2003; Werren et al., 2004; Grillenberger et al., 2008; Lynch \& Desplan, 2010). The use of $N$. vitripennis as a model species found its temporary pinnacle in the recent publication of the complete genome of this species and its sibling taxa $N$. giraulti and $N$. longicornis (Werren et al., 2010). A recent taxonomic revision of $D$. microgastri confirmed it is a highly polyphagous generalist that uses the pupal stages of various holometabolic insect species and has no habitat preferences (Peters \& Abraham, 2010; Peters \& Baur, 2011).

The aim of this study is to characterize the host finding behaviour of a specialist and a generalist parasitoid in order to obtain a better understanding how they each search for hosts. This involved experimental analyses of the species' olfactory orientation and behaviour in the absence of olfactory cues. All the experiments are designed to test the parasitoids' innate behavioural repertoire, excluding learning and differences in learning ability. Vet et al. (1998) describe host finding behaviour as a dynamic process that depends on the learning status of the individual parasitoid. Thus, the parameters used in this study represent only a limited part of parasitoid host finding biology.

In tests on olfactory orientation the reaction to cues of the host habitat and of suitable and unsuitable host species were tested in an olfactometer. These were expected to reveal differences between species, since olfactory cues are known to be used in various ways and to different degrees by parasitoids from different superfamilies (e.g., Jones, 1986; Sereno \& Neves, 1994; Hedlund et al., 1996; Geervliet et al., 2000; Sullivan et al., 2000; Schlein, 2002; Steidle et al., 2003). The tests, which did not include olfactory cues, were designed to determine and characterize differences in locomotor activity, ability to find and enter simulated host habitats (in the following termed "searching activity") and day-night-activity of the two parasitoids. Some of these parameters were studied before for other purposes (King et al., 2000; King, 2007) the others were newly established in this study. 


\section{MATERIAL AND METHODS}

\section{Laboratory cultures}

Laboratory cultures of both parasitoids were maintained by rearing them on puparia of Calliphora vomitoria (Linnaeus, 1758) (Diptera: Calliphoridae) in Petri dishes at room temperature. Puparia, aged 4-6 days, were freeze-killed at $-18^{\circ} \mathrm{C}$ and thawed before used for rearing the parasitoids.

The breeding stock of $N$. vitripennis was originally reared from Protocalliphora azurea (Fallén, 1816) (Diptera: Calliphoridae) collected from birds' nests. The breeding stock of $D$. microgastri was originally reared from Triarthria setipennis (Fallén, 1810) (Diptera: Tachinidae). Both stocks originated from Hamburg, Germany. There are voucher specimens of both laboratory stocks deposited at the Zoologisches Museum Hamburg (ZMH).

\section{Laboratory tests}

The temperature in all the tests was $22-24^{\circ} \mathrm{C}$. Individual status of the parasitoid females tested was standardized in terms of age, mating and feeding status, exterior condition and experience. Specimens were 3-6 days old, mated and fed on moistened raisins. Females of similar size and with intact antennae were used. All females had no previous experience of oviposition or contact with hosts. In olfactometer and locomotor activity tests females were acclimated for $5 \mathrm{~min}$.

\section{Olfactometer tests}

In this study an airflow olfactometer of novel design was used, in which the parasitoids could walk freely on a vertical gauze screen. The openings of the horizontal substrate tubes are attached to the vertical screen forming distinct substrate sectors on the screen in frontal view. The time the parasitoids spent in these sectors was recorded. Fig. 1 shows the basic structure of the apparatus. A more detailed description can be found in Peters \& Abraham (2009). This olfactometer has advantages over other olfactometers in terms of minimal disturbance, data evaluation and more natural behaviour of the specimens tested (Schlein, 2002; Peters \& Abraham, 2009).

In every trial 15 females of the species studied were put into the test chamber. One of the substrate tubes contained a test substrate and the other was empty and acted as the control.

Test substrates included: (1) material obtained from Parus spp. nests the preceding breeding season and stored in airtight plastic bags, (2) earwig faeces (max. 3 days old), (3) 40 living specimens (20 females, 20 males) of the common earwig Forficula auricularia Linnaeus, 1758, (4) 30 puparia of the blowfly Calliphora vomitoria (4-6 days old), (5) 30 puparia of the earwig fly Triarthria setipennis (Diptera: Tachinidae) (4-6 days old) and (6) 20 cocoonless pupae of the wax moth Galleria mellonella (Linnaeus, 1758) (Lepidoptera: Pyralidae).

Birds' nest material is the habitat of $N$. vitripennis, earwigs and earwig faeces were chosen as representatives of the habitat of D. microgastri. All other substrates are host cues. The blowfly is a natural host of $N$. vitripennis and the earwig fly of D. microgastri. Both these fly species are suitable laboratory hosts for both parasitoids. G. mellonella is unsuitable for $N$. vitripennis, but suitable for $D$. microgastri.

Measurement of the duration of stay: One female was randomly selected before entering any substrate sector. When the female next entered a substrate sector the measurement was started. If the female left the sector, the measurement was stopped, but was then continued if the female returned within the next seven seconds. This time span was defined in pre-tests. Leaving the sector with the cue and returning after a short while is considered klinotactic behaviour, which is a typical part of a parasitoids' behaviour. If a tested female flew off a sector



Fig. 1. Olfactometer with a vertical gauze screen as used in this study; $\mathrm{a}$ - gauze cover, $\mathrm{b}$ - test chamber, $\mathrm{c}$ - vertical test screen, $\mathrm{d}$ - substrate tubes, e - substrate sectors (i.e., openings of substrate tubes on back of test screen) and $\mathrm{f}-$ airflow. (Figure taken from Peters \& Abraham, 2009.)

during measurement, the measurement was omitted. Tests were likewise not used if during a measurement the female was disturbed by another female.

In total, for every substrate and every species 120 measurements of the time the parasitoid spent in a substrate sector were made. The position of the substrate tubes was changed once during each trial to exclude a bias for a particular side. Parasitoid females and substrates were changed after 60 measurements. For the empty control and the blowfly puparia, which were more intensively studied in a first trial, a total of 720 measurements were made.

\section{Locomotor activity}

The activity tests were conducted in a glass container. The container consisted of an inverted 51 aquarium $(22 \times 25 \times 18$ $\mathrm{cm})$ placed on a black cardboard sheet. Locomotor activity was measured over a period of $10 \mathrm{~min}$ each in terms of (1) the distance the parasitoid ran, (2) the proportion of the time it was active and (3) the number of times it flew. To ensure that the parasitoid ran equally on all of the walls of the glass container it was illuminated equally from all sides by the light from $15 \mathrm{~W}$ bulbs. In every trial a single female was used. These measures of locomotor activity were recorded for each female consecutively. In total, every test was done 40 times.

The distance a parasitoid ran was measured over a period of $10 \mathrm{~min}$. The track of a running female was marked on the outside of the container with a waterproof colored pen. If the wasp left the glass wall (except for a split second flight), the test was interrupted until it returned. The length of the track was measured using a map distance measurer (K\&R Kartenmesser) and transformed into centimetres.

The proportion of time active was measured as the proportion of 10 min that the parasitoid was locomotorily active, i.e., running or flying. The number of times each wasp flew in the 10 min were recorded on a hand counter.

\section{Searching and day-night activity}

The container for these tests measured $87.5 \times 50 \times 50 \mathrm{~cm}$. Eight $125 \mathrm{ml}$ catching bottles were attached to the walls of the container. The openings of the bottles were covered with Parafilm. A bent black straw was inserted through the Parafilm and served as the entrance to each bottle. The straw was $18 \mathrm{~cm}$ long and had a diameter of $5 \mathrm{~mm}$. Entrance openings of the straws were stuck to and level with the surface of the walls of the container. During the tests the container was illuminated from all sides by five $40 \mathrm{~W}$ bulbs each positioned $45 \mathrm{~cm}$ from a wall of the container. The container was placed on aluminium foil, which served to reflect light from below.

Before testing, parasitoids were kept for a minimum of four days in the same day-night-rhythm $(12: 12)$ as used in the tests. Tests were started between 7 and 8 a.m. or p.m. Each test lasted for $24 \mathrm{~h}$. A total of 250 females of $N$. vitripennis or D. micro- 
gastri, respectively, were put into the container for each test, which were replicated 6 times for each species.

The number of females caught in the traps were counted first after $12 \mathrm{~h}$ and then after $24 \mathrm{~h}$. The first count was of the living animals in the traps. Prior to the second count the specimens were freeze-killed.

\section{Statistical analysis}

Means of the duration of time the parasitoids spent on the substrate sectors, the distance they ran, proportion of time they were active, number of flights and number of specimens caught were compared using Wilcoxon-Mann-Whitney rank sum tests for not normally distributed data and t-tests for normally distributed data. Tests for normal distribution of data were made using the Kolmogorov-Smirnov-test. The control of false discovery rate and the correction of significance levels were made following the procedure described by Benjamini \& Hochberg (1995) and recommended by Garcia (2003) for ecological studies. All the data analysis was carried out using SPSS 17.0 for Windows (Norusis, 2008).

\section{RESULTS}

\section{Olfactometer results}

$N$. vitripennis females significantly reacted to all the substrates offered. The birds' nest material was most attractive, with a median duration of stay greater than for all the other substrates (Fig. 2A and Table 1). The reaction to the odour of natural hosts (blowfly puparia) and taxonomically related hosts (earwig fly puparia) was strong with that to blowflies the strongest. $N$. vitripennis females reacted to the odour from earwig faeces, earwigs and wax moth pupae even though these substrates are not associated with its hosts or habitat. In summary this parasitoid showed strong reactions to olfactory cues associated with its hosts and their habitat and other potential hosts and a weaker but definite reaction to cues of other habitats and unsuitable hosts.

D. microgastri females generally showed weaker olfactory reactions (Fig. 2B, Table 2). The exceptions were the substrates associated with the broad habitat range of $D$. microgastri (earwig faeces and earwigs); the females reacted significantly stronger to these earwig associated cues than to all other substrates. The female responses to olfactory cues associated with puparia of the earwig fly and blowfly (host cues), and the control were significantly different (Wilcoxon-Mann-Whitney test), but the medians are similar (Fig. 2B, Table 1). This indicates there are only small differences in the responses of this wasp to these cues, i.e., the reaction to host cues is present but weak. There was no reaction to birds' nest material and wax moth pupae. In contrast to $N$. vitripennis, wax moth pupae are a suitable host for D. microgastri. In summary this parasitoid showed a weak reaction to olfactory cues associated with the habitat and some suitable host species and no reaction to the other olfactory cues tested.

The rank sum test indicates there is an interspecific difference in the time spent on the control sector (Table 2). However, again the medians are similar, which indicates a slight difference in running speed that does not affect the general conclusions about the interspecific differences.


Fig. 2. Time spent by the two parasitoids on the various test substrate sectors in the olfactometer. A - Nasonia vitripennis, B - Dibrachys microgastri; boxes show upper and lower quartile and median; whiskers extend 1.5 times interquartile range; outliers not shown.

Fig. 2 shows the length of time each species spent on each of the various sectors and Table 1 and 2 list the p-values of all intra- and interspecific comparisons along with Benjamini-Hochberg corrected significance levels (Benjamini \& Hochberg, 1995).

\section{Locomotor activity}

The distance covered by running in $10 \mathrm{~min}$ by $D$. microgastri was significantly greater than by $N$. vitripennis (t-test, $\mathrm{p}<0.001$, Fig. 3A). The distance covered is remarkably high for an animal that is only $2-3 \mathrm{~mm}$ long: On average, the females ran $611 \mathrm{~cm}$ in $10 \mathrm{~min}$, with a maximum of $903 \mathrm{~cm}$. This means, that in one hour a female can run about $36 \mathrm{~m}$. The track is not straight but oscillates from side to side with a low amplitude. Even 
TABLE 1. Intraspecific comparisons of time spent in the various substrate sectors in the olfactometer (Wilcoxon-Mann-Whitney tests) with p-values and Benjamini-Hochberg corrected significance levels; substrates with higher medians are in bold print; if none of the substrates are in bold print the medians are similar.

\begin{tabular}{|c|c|c|c|c|c|c|c|}
\hline \multicolumn{4}{|l|}{ N. vitripennis } & \multicolumn{4}{|l|}{ D. microgastri } \\
\hline Substrates & $\mathrm{p}$ & Sign. level & & Substrates & $\mathrm{p}$ & Sign. level & \\
\hline earwigs: birds' nest material & $<0.001$ & 0.002 & + & earwigs: birds' nest material & $<0.001$ & 0.002 & + \\
\hline earwigs: blowfly puparia & $<0.001$ & 0.002 & + & earwigs: blowfly puparia & $<0.001$ & 0.002 & + \\
\hline earwigs: control & $<0.001$ & 0.002 & + & earwigs: control & $<0.001$ & 0.002 & + \\
\hline earwig fly puparia: birds' nest material & $<0.001$ & 0.002 & + & earwig fly puparia: birds' nest material & $<0.001$ & 0.002 & + \\
\hline earwig fly puparia: control & $<0.001$ & 0.002 & + & earwig fly puparia: control & $<0.001$ & 0.002 & + \\
\hline earwig faeces: birds' nest material & $<0.001$ & 0.002 & + & earwig faeces: birds' nest material & $<0.001$ & 0.002 & + \\
\hline earwig faeces: blowfly puparia & $<0.001$ & 0.002 & + & earwig faeces: blowfly puparia & $<0.001$ & 0.002 & + \\
\hline earwig faeces: control & $<0.001$ & 0.002 & + & earn & $<0.001$ & 0.002 & + \\
\hline birds' nest material: wax moth pupae & $<0.001$ & 0.002 & + & birds' nest material: wax mo & 0.920 & 0.05 & - \\
\hline birds' nest material: blowfly puparia & $<0.001$ & 0.002 & + & l: blowfly puparia & 0.020 & 0.036 & + \\
\hline birds' nest material: control & $<0.001$ & 0.002 & + & birds' nest materia & 0.168 & 0.043 & - \\
\hline wax moth pupae: blowfly puparia & $<0.001$ & 0.002 & + & wax moth pupae: blowfly puparia & 0.012 & 0.033 & + \\
\hline wax moth pupae: control & $<0.001$ & 0.002 & + & wax moth pupae: control & 0.2 & 0.045 & - \\
\hline blowfly puparia: control & $<0.001$ & 0.002 & + & blowfly puparia: control & $<0.001$ & 0.002 & + \\
\hline earwig fly puparia: blowfly puparia & 0.001 & 0.036 & + & earwig fly puparia: blowfly puparia & 0.005 & 0.031 & + \\
\hline earwig fly puparia: wax moth pupae & 0.013 & 0.038 & + & earwig fly puparia: wax moth pupae & $<0.001$ & 0.002 & + \\
\hline earwig fly puparia: earwig faeces & 0.040 & 0.041 & + & earwig fly puparia: earwig faeces & 0.1 & 0.041 & - \\
\hline earwigs: wax moth pupae & 0.184 & 0.043 & - & earwigs: wax moth pupae & $<0.001$ & 0.002 & + \\
\hline earwigs: earwig fly puparia & 0.190 & 0.045 & - & earwigs: earwig fly puparia & 0.030 & 0.038 & + \\
\hline earwigs: earwig faeces & 0.403 & 0.048 & - & earwigs: earwig faeces & 0.818 & 0.048 & - \\
\hline earwig faeces: wax moth pupae & 0.685 & 0.05 & - & earwig faeces: wax moth pupae & $<0.001$ & 0.002 & + \\
\hline
\end{tabular}

the species with a lower running activity, $N$. vitripennis, reached a mean of almost $400 \mathrm{~cm}$ in $10 \mathrm{~min}$.

$N$. vitripennis spends proportionly less time active than D. microgastri (t-test, $\mathrm{p}<0.001$, Fig. 3B). The less time spent running can at least in part explain the shorter distance covered by $N$. vitripennis. Running speed was not specifically measured, but was approximately equal with the D. microgastri females tending to run slightly faster. The time the parasitoids spent stationary was mainly used for grooming antennae and wings.

In contrast to running activity, $N$. vitripennis was significantly more flight active than $D$. microgastri (U-test, $\mathrm{p}<0.001$, Fig. 3C). The difference is striking. $N$. vitripennis flew on average 41 times in $10 \mathrm{~min}$ with maximum of more than 100 flights in 10 min. For $D$. microgastri the mean number of flights was only 7 with

TABLE 2. Interspecific comparison of time spent in the various substrate sectors in the olfactometer by $N$. vitripennis and D. microgastri; sign. levels with Benjamini-Hochberg corrections.

\begin{tabular}{lcccc}
\hline Substrate & $\mathrm{p}$ & $\begin{array}{c}\text { Sign. } \\
\text { level }\end{array}$ & & $\begin{array}{c}\text { Species with } \\
\text { higher median }\end{array}$ \\
\hline birds' nest material & $<0.001$ & 0.007 & + & N. vitripennis \\
wax moth pupae & $<0.001$ & 0.007 & + & N. vitripennis \\
blowfly puparia & $<0.001$ & 0.007 & + & N. vitripennis \\
control & $<0.001$ & 0.007 & + & similar \\
earwig fly puparia & 0.004 & 0.036 & + & N. vitripennis \\
earwig faeces & 0.605 & 0.043 & - & similar \\
earwigs & 0.993 & 0.05 & - & N. vitripennis \\
\hline
\end{tabular}

the data mainly consisting of low numbers (median $=4.5$, interquartile range 2-7.75).

\section{Searching and day-night-activity}

The females of both species found and entered the entrance holes of the simulated habitats, i.e., showed high searching activity. There were many parasitoids in the catching bottles after $24 \mathrm{~h}$ (Fig. 4). A greater number of $N$. vitripennis was trapped but the difference was not significant (t-test, $\mathrm{p}>0.07$ ). A total of 250 females of both species were tested of which $25.6 \%$ of the $N$. vitripennis and $16.7 \%$ of the D. microgastri were trapped.

The higher value for $N$. vitripennis resulted from an interspecific difference in the day-night-activity. There was no difference in the activity of both species during the day (t-test, $\mathrm{p}>0.9$, Fig. 4). N. vitripennis, however, is also active at night, although less than during the day $(\mathrm{p}<$ 0.001 ), and significantly more $N$. vitripennis than $D$. microgastri were caught during the night (t-test, $\mathrm{p}<$ 0.01). D. microgastri did not actively search at night and as a consequence very few specimens were caught.

Fig. 5 summarizes the different ways in which the two parasitoids find hosts by combining the most important host finding characteristics revealed by this study with host and habitat range data in the literature (Peters, 2010a; Peters \& Baur, 2011).

\section{DISCUSSION}

The connection between habitat specificity and a strong reaction to olfactory cues, which is shown here for $N$. vitripennis and previously reported by Edwards (1954), 



Fig. 3. Distance covered by running, percentage of the time active and number of times the two parasitoids flew during a period of 10 min. A - means of the distances covered, B - means of percentages active, $\mathrm{C}$ - means of number of flights; error bars show standard error of mean.

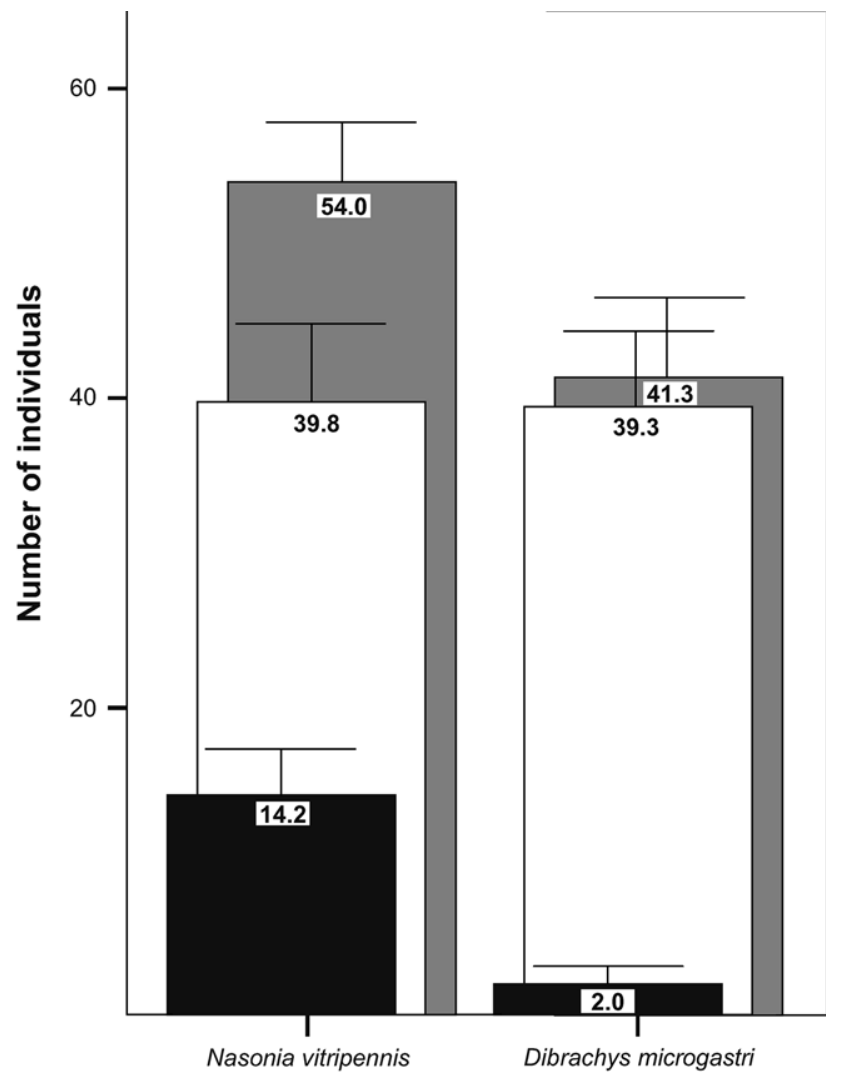

Fig. 4. Mean number of specimens of the two parasitoids caught after $24 \mathrm{~h}$ (grey) and during the day (12 h; white) and night (12 h; black) when searching in the absence of olfactory cues; number of specimens tested in each case: 250 ; error bars show standard error of mean. occurs widely in parasitoids and appears to be one of the common patterns in parasitoid host finding. It is recorded for parasitoids of saprophagous (e.g., Stafford et al., 1984; Reznik et al., 1992; Sereno \& Neves, 1994) and phytophagous species of host (e.g., Sullivan et al., 2000; Völkl \& Sullivan, 2000).

The results of the olfactometer tests match the biology of $N$. vitripennis as a specialist parasitoid of Diptera inhabitating birds' nests and additionally carrion (Peters, 2010a; Peters \& Abraham, 2010). Especially, the response to the olfactory cue of the host habitat is strong. The material from a birds' nest is a reliable cue of a habitat where ornithoparasitic, necrophagous or other hosts regularly occur (Peters \& Abraham, 2004; Peters, 2007; Peters \& Abraham, 2010). Wylie (1958) and Schlein (2002) also record a significant reaction of $N$. vitripennis to carrion, which can be advantageous for this parasitoid as nests often contain carrion and suitable hosts feed on carrion. This reaction might explain the repeated records of this parasitoid from carrion (e.g., Grassberger $\&$ Frank, 2004). The significant reaction to natural hosts (blowfly puparia) and taxonomically related hosts (earwig fly puparia) (Fig. 2A) indicates this is an important part of the host finding process. The effective cues are probably kairomones produced by the living hosts. The reaction to kairomones is also recorded, e.g., for Leptopilina heterotoma (Figitidae), Lariophagus distinguendus (Pteromalidae) and Aphidius nigripes (Aphidiidae) (van Alphen et al., 1984; Bouchard \& Cloutier, 1985; Steidle et al., 2003). However, cues associated with living hosts are not 


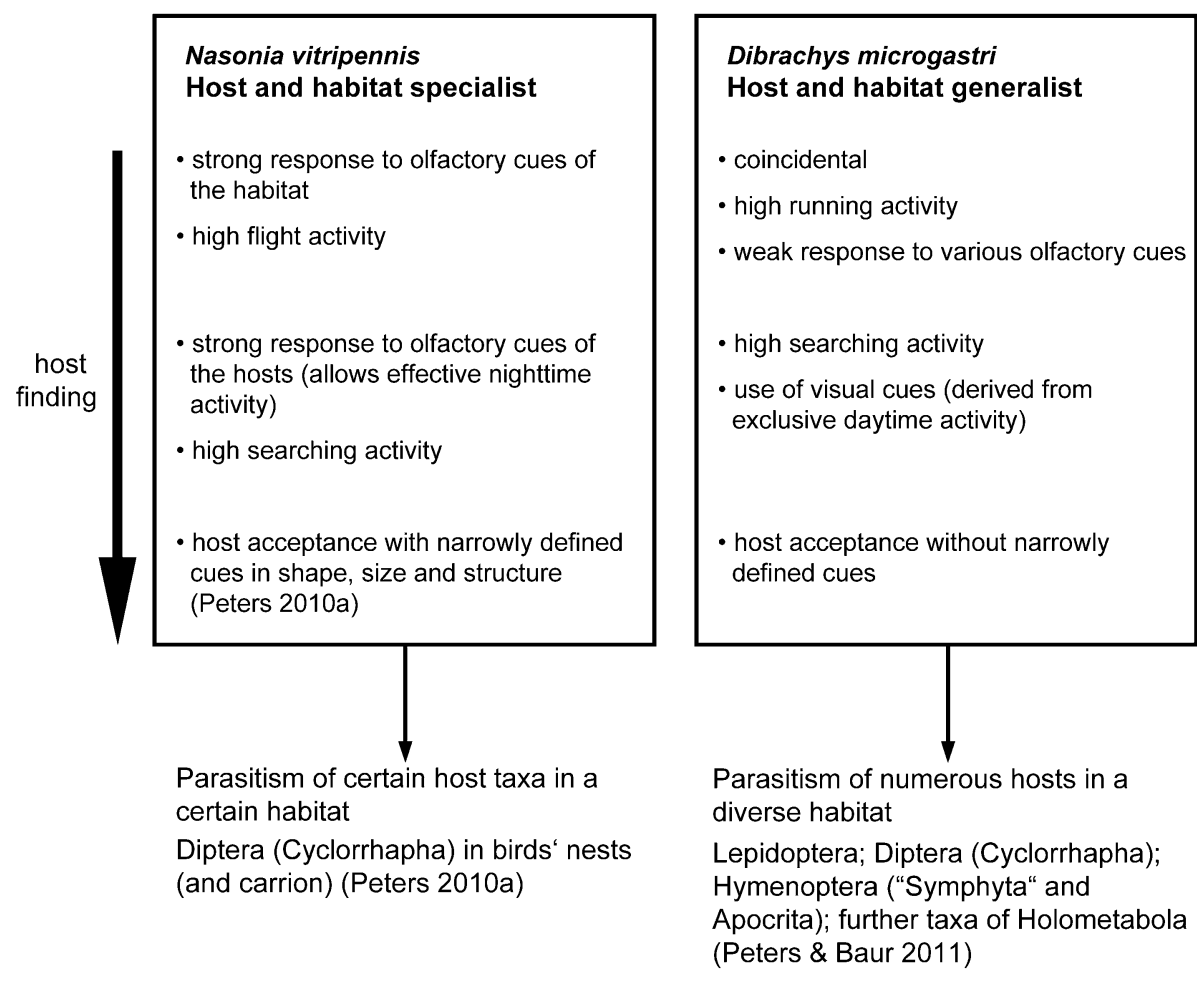

Fig. 5. Diagram depicting two ways of finding a host: Host finding steps recorded in this study matched with the life history traits of both species.

exclusively responsible for the parasitoids' reaction as mated $N$. vitripennis females also react to the odour of freeze-killed host puparia (Peters, 2007; Steiner \& Ruther, 2009). The cue involved in this reaction is unclear, but maybe the odour of dead puparia is more similar to carrion than to the living host. $N$. vitripennis also reacts to hosts (Galleria mellonella) that are outside its host range (Fig. 2A). This means that a positive olfactory reaction does not necessarily result in parasitism, i.e., it is not decisive in host acceptance. The reaction to olfactory cues that are not associated with this species' hosts or their habitat (earwigs and earwig faeces), although rather weak, is interpreted as a general reaction to olfactory cues that might indicate the presence of suitable hosts. It is possible that this reaction is even stronger if specific cues, such as birds' nest material, are absent. This general reaction to olfactory cues might explain host records, e.g., from dung-breeding Diptera (Noyes, 2009).

$D$. microgastri did not respond as strongly to olfactory cues as $N$. vitripennis. It did not react to the odour of hosts (wax moth G. mellonella) or only weakly (earwig fly and blowfly) (Fig. 2B). It is unknown why it differs in its response to the odour of suitable host species. However, it can be concluded that medium and short range orientation as well as host acceptance by $D$. microgastri are mediated by factors other than olfactory cues. The strongest reaction recorded for $D$. microgastri is to earwig associated host habitat cues. This reaction is interpreted as an unspecific reaction to general habitat associated olfactory cues, which indicate possible presence of hosts of this polyphagous species. A similar interpretation might apply to its response to the odour of carrion (Schlein, 2002), frass of different species of Lepidoptera (Chuche et al., 2006) and pine logs (Boone et al., 2008). This unspecific reaction might also account for records from dung communities (Hoebeke \& Rutz, 1988; Floate et al., 1999). This interpretation is similar to that proposed in the review of Steidle \& van Loon (2003), which reports the use of infochemicals like the olfactory cues associated with habitats, not only by specialist species but also by extremely generalist species. This use of all accessible cues is beneficial for all kinds of host or prey searching species. However, the results recorded for $D$. microgastri are difficult to interpret. Possible sources of misinterpretation include: (1) Intraspecific strains that differ in host and habitat preference and host finding, which commonly occur in hymenopteran parasitoids (Godfray, 1994). In our case this explanation seems implausible, since our ecological and taxonomic studies on $D$. microgastri have not revealed an earwig associated strain or any other host specific strain (Peters, 2007; Peters \& Abraham, 2010; Peters \& Baur, 2011). We assume that there are no such strains in the polyphagous D. microgastri and that the olfactory behaviour recorded is characteristic of the whole species. (2) There might be another cue, which was not tested in this study or any of the other studies cited above, to which $D$. microgastri females react more strongly. Again no sign of such a cue is revealed by our previous studies on this species.

The three measurements of locomotor activity provided further insights into host finding by the two species: (1) $N$. vitripennis: In the absence of olfactory cues, this spe- 
cies exhibits high flight activity, i.e., females leave their position by flying. The numerous flights are interpreted as searching for orientation cues. Only short-distance flights were possible in the experimental setup used. In the field these flights are longer and occur over a wide range of heights and often at a great height (Abraham, 1985; Schröder, 1997) where birds' nests can be found. The short distance covered by running can be explained by the high proportion of time spent stationary and the numerous flights (interrupted activity). The proportion of time spent stationary is similar to that recorded by King et al. (2000) and King (2007) for mated females. (2) D. microgastri: This species covers a great distance by running and rarely flies when searching for orientation cues of low specificity or even for directly detectable hosts. This species runs rapidly and continuously (Figs 3A-B). During a single day a female of $D$. microgastri is able to search a large area and as a consequence many hosts are found during this non-mediated, random, rapid running. Hoffmeister \& Gienapp (2001) show that random host search, e.g., by rapid running, can be effective if the accessibility of hosts is constantly changing in space, in their case due to the mobility of the hosts. In the case of $D$. microgastri the accessibility constantly changes as many hosts that differ greatly in biology will be encountered and parasitized.

However, the characteristics of the areas searched in the field and those that the parasitoids experienced in the laboratory are not identical. Their natural habitat is much more diverse and complex and this is likely to result in some differences in the way they search for hosts in the field and in the laboratory experiments reported here.

For the experiments on searching and day-night-activity I tried to create a more realistic habitat scenario. The containers and the entrances to the traps in these experiments simulate hidden habitats like small cavities in wood or under bark, where the hosts of these parasitoids occur in the field. Both $N$. vitripennis and D. microgastri show a high searching activity (Fig. 4). The finding of the entrances to the traps is primarily a result of chance, which, especially in D. microgastri, is a consequence of the extensive area it searched. The entering and walking through the dark tube entrance indicates active searching for hosts in the absence of olfactory cues. Other dipterophagous pteromalids, for example Pachycrepoideus vindemmiae (Rondani, 1875) (Chalcidoidea: Pteromalidae), do not enter such cavities in a similar scenario (Peters, 2010b). As mentioned before, a female of D. microgastri can run a great distance during its search for hosts. Therefore it is likely that in this way it is able to find hidden places, cavities and hosts. Combined with polyphagy this is an effective parasitoid strategy.

$N$. vitripennis is active both during the day and night, while $D$. microgastri is only active during the day. This strongly suggests that visual cues play a relatively greater role in the search for hosts in D. microgastri, while tactile cues are more important in $N$. vitripennis. The visual sense is also important for $N$. vitripennis as this species can see and use colors (Oliai \& King, 2000), but it does not depend only on visual cues as it found the entrances to the traps also at night. As there were no olfactory cues it must have been responding to tactile cues. In its natural habitat (nest cavities or boxes and nest material) $N$. vitripennis has to search largely without the aid of visual cues. This parasitoid is able to penetrate deeply into tightly packed substrates, whereas $D$. microgastri mostly searches on the surface of such substrates (Schlein, 2002). This again indicates a predominantly visual host search in D. microgastri and a visual and tactile mediated search in $N$. vitripennis.

\section{CONCLUDING CONSIDERATIONS}

These two closely related parasitoid species, which overlap in host and habitat range (Peters, 2010a; Peters \& Abraham, 2010; Peters \& Baur, 2011), differ greatly in numerous life history traits. While Harvey (2008) presents similar results for the reproductive strategies of two closely related species of Ichneumonidae, the two species of Pteromalidae used in this study differ in the way they search for hosts, i.e., they have evolved two different ways of finding hosts. The specialist $N$. vitripennis can reliably locate its hosts and their habitat by means of olfactory cues. As this species mainly uses olfactory cues it can also search for hosts at night. However, this reliability is also its limitation. Once the habitat is found, only hosts within this habitat can be parasitized. The evolutionary responses to this limitation may be the use of various host species within the habitat (Peters, 2010a; Peters \& Abraham, 2010), high parasitism rates (Grillenberger et al., 2008; Peters \& Abraham, 2010), fast development, and synchronisation of its phenology with that of the main host species and the birds' breeding season (Schlein, 2002). The generalist D. microgastri finds its hosts mainly by searching a great area by continually running, finding and entering cavities and using visual cues. Its limitation is the low reliability and coincidence. The host range of D. microgastri is greater than that of many other generalist parasitoids (e.g., Hedlund et al., 1996; Geervliet et al., 2000; Steidle et al., 2003). It can be best compared with a generalist predator as almost any host (or prey) it encounters is parasitized (or consumed).

If both species occur together, which is the case in birds' nests (Peters, 2007; Abraham \& Peters, 2008; Peters \& Abraham, 2010) or under laboratory conditions, D. microgastri is the inferior species. The development time is shorter and fecundity is higher in $N$. vitripennis (Schlein, 2002). On the other hand, D. microgastri can use hosts, that $N$. vitripennis cannot find or, if found, cannot successfully parasitize.

These still incomplete insights into two very different ways of finding hosts indicate that a specific combination of host finding mechanisms, from initial host habitat location to final host acceptance, characterizes each parasitoid species and shapes parasitoid diversity. This diversity is to a large extent a reflection of the diversity of host finding mechanisms.

ACKNOWLEDGEMENTS. The author thanks R. Abraham (Hamburg) for initial ideas and support throughout my studies 
and L. Krogmann (Stuttgart), K. Schütte (Hamburg), B. Misof (Bonn), N. Szucsich (Hamburg), J. Harvey (Wageningen) and an anonymous reviewer for helpful comments on the manuscript.

\section{REFERENCES}

AвRAHAM R. 1985: Nasonia vitripennis an insect from birds' nests (Hymenoptera: Chalcidoidea: Pteromalidae). Entomol. Gen. 10: 121-124.

Abraham R. \& Peters R.S. 2008: Nestboxes as habitat for insects, especially for flies and their parasitoids. Vogelwarte 46: 195-205 [in German with English abstr.].

Alphen J.J.M. van, Lenteren J.C. van, Nell H.W. \& Eebes H. 1984: The response of a polyphagous parasitoid (Leptopilina heterotoma (Thompson)) to a kairomone produced by one of its hosts (Drosophila melanogaster Meigen). Neth. J. Zool. 34: 215-219.

Benjamini Y. \& Hochberg Y. 1995: Controlling the false discovery rate: a practical and powerful approach to multiple testing. J. R. Stat. Soc. (B) 57: 289-300.

Boone C.K., Six D.L., Zheng Y. \& RAFFA K.F. 2008: Parasitoids and dipteran predators exploit volatiles from microbial symbionts to locate bark beetles. Environ. Entomol. 37: 150-161.

Bouchard Y. \& Cloutier C. 1985: Role of olfaction in hostfinding by aphid parasitoid Aphidius nigripes (Hymenoptera: Aphidiidae). J. Chem. Ecol. 11: 801-808.

Chuche J., Xuéreb A. \& Thiéry D. 2006: Attraction of Dibrachys microgastri (Hymenoptera: Pteromalidae) to its host frass volatiles. J. Chem. Ecol. 32: 2721-2731.

EDWARDS R.L. 1954: The host-finding and oviposition behaviour of Mormoniella vitripennis (Walker) (Hym., Pteromalidae), a parasite of muscoid flies. Behaviour 7: 88-112.

Floate K.D., Khan B. \& Gibson G. 1999: Hymenopterous parasitoids of filth fly (Diptera: Muscidae) pupae in cattle feedlots. Can. Entomol. 131: 347-362.

Gadau J., Page R.E. JR \& Werren J.H. 1999: Mapping of hybrid incompatibility loci in Nasonia. Genetics 153: $1731-1741$

GARCIA L.V. 2003: Controlling the false discovery rate in ecological research. Trends Ecol. Evol. 18: 553-554.

Geervliet J.B.F., Verdel M.S.W., Snellen H., Schaub J., Dicke M. \& Vet L.E.M. 2000: Coexistence and niche segregation by field populations of the parasitoids Cotesia glomerata and C. rubecula in the Netherlands: predicting field performance from laboratory data. Oecologia 124: 55-63.

Godfray H.C.J. 1994: Parasitoids. Behavioural and Evolutionary Ecology. Princeton University Press, Princeton, NJ, $473 \mathrm{pp}$.

Grassberger M. \& FranK C. 2004: Initial study of arthropod succession on pig carrion in a Central European urban habitat. J. Med. Entomol. 41: 511-523.

Grillenberger B.K., Koevoets T., Burton-Chellew M.N., Sykes E.M., Shuker D.M., van de Zande L., BiJlsma R., Gadau J. \& Beukeboom L.W. 2008: Genetic structure of natural Nasonia vitripennis populations: validating assumptions of sex-ratio theory. Mol. Ecol. 17: 2854-2864.

Hedlund K., Vet L.E.M. \& Dicke M. 1996: Generalist and specialist parasitoid strategies of using odours of adult drosophilid flies when searching for larval hosts. Oikos 77: 390-398.

Hoebeke E.R. \& Rutz D.A. 1988: Trichomalopsis dubius (Ashmead) and Dibrachys microgastri (Walker): Newly discovered pupal parasitoids (Hymenoptera: Pteromalidae) of house flies and stable flies associated with livestock manure. Ann. Entomol. Soc. Am. 81: 493-497.
HoffMeister T.S. \& GienAPP P. 2001: Discrimination against previously searched, host-free patches by a parasitoid foraging for concealed hosts. Ecol. Entomol. 26: 487-494.

JONES R.L. 1986: Orientation by insect parasitoids. In Payne T.L., Birch M.C. \& Kennedy C.E.J. (eds): Mechanisms in Insect Olfaction. Clarendon Press, Oxford, pp. 149-156.

KING B.H. 2007: The effect of exposure to conspecifics on restlessness in the parasitoid wasp Nasonia vitripennis (Hymenoptera: Pteromalidae). Can. Entomol. 139: 678-684.

KING B.H., Grimm K.M. \& ReNo H.E. 2000: Effects of mating on female locomotor activity in the pteromalid wasp Nasonia vitripennis (Hymenoptera: Pteromalidae). Environ. Entomol. 29: 927-933.

LaSalle J. \& Gauld I.D. 1991: Parasitic Hymenoptera and the biodiversity crisis. Redia 74 (Appendix): 315-334.

Lynch J.A. \& Desplan C. 2010: Novel modes of localization and function of nanos in the wasp Nasonia. Development 137: 3813-3821.

Noyes J.S. 2009: Universal Chalcidoidea Database. World Wide Web Electronic Publication. www.nhm.ac.uk/researchcuration/projects/chalcidoids/index [accessed 09. Jan. 2009].

Norusis M.J. 2008: SPSS 17.0 Guide to Data Analysis, Prentice Hall, Upper Saddle River, NJ, 672 pp.

Oliat S.E. \& King B.H. 2000: Associative learning in response to color in the parasitoid wasp Nasonia vitripennis (Hymenoptera: Pteromalidae). J. Insect Behav. 13: 55-69.

PeTERS R. 2007: Interaktionen zwischen Wirten und Parasitoiden: Nahrungsnetzstruktur, Wirtsspektren und Wirtsfindung am Beispiel der Arten aus Vogelnestern. Ph.D. thesis. University of Hamburg. www.sub.uni-hamburg.de/opus/volltexte/ 2007/3234/pdf/DissertationPeters.pdf

Peters R.S. 2010a: Host range and offspring quantities in natural populations of Nasonia vitripennis (Walker, 1836) (Hymenoptera: Chalcidoidea: Pteromalidae). J. Hymen. Res. 19: $128-138$.

Peters R.S. 2010b: New records and notes on the life history of Pachycrepoideus vindemmiae (Rondani, 1875) (Hymenoptera: Chalcidoidea: Pteromalidae). Mitt. Hamb. Zool. Mus. Inst. 106: 39-49.

Peters R. \& Abraham R. 2004: Interactions between parasitoid Hymenoptera (Chalcidoidea: Pteromalidae) and Diptera: Cyclorrhapha in nests of cavity-nesting birds. Entomol. Gen. 27: 133-141.

Peters R.S. \& Abraham R. 2009: A wind tunnel olfactometer of novel design: Testing the response to substrate volatiles on a vertical gauze screen. Entomol. Mitt. Zool. Mus. Hamburg 15: 127-133.

Peters R.S. \& Abraham R. 2010: The food web of parasitoid wasps and their non-phytophagous fly hosts in birds' nests (Hymenoptera: Chalcidoidea, and Diptera: Cyclorrhapha). $J$. Nat. Hist. 44: 613-626.

Peters R.S. \& Baur H. 2011: A revision of the Dibrachys cavus species complex (Hymenoptera: Chalcidoidea: Pteromalidae). Zootaxa 2937: 1-30.

Pultz M.A. \& Leaf D.S. 2003: The jewel wasp Nasonia: Querying the genome with haplo-diploid genetics. Genesis 35: 185-191.

RezniK S.Y., Chernoguz D.G \& Zinovjena K.B. 1992: Host searching, oviposition preferences and optimal synchronization in Alysia manducator (Hymenoptera: Braconidae), a parasitoid of the blowfly, Calliphora vicina. Oikos 65: 81-88.

SCHLEIN O. 2002: Nischendifferenzierung und Reduktion von interspezifischer Konkurrenz zwischen den Parasitoiden Nasonia vitripennis (Walker 1836) und Dibrachys cavus (Walker 1835) (Hymenoptera: Pteromalidae) bei der Wirtssuche in Vogelnestern. Ph.D. thesis. University of Hamburg. 
www.sub.uni-hamburg.de/opus/volltexte/2002/860/pdf/ dissertation.pdf

SCHRÖDER H. 1997: Differenzierung zweier Ökotypen bei Nasonia vitripennis (Walker 1836) (Hymenoptera: Pteromalidae). Berichte aus der Biologie, Shaker Verlag, Aachen, 125 pp.

SERENo F.T.P.S. \& Neves D.P. 1994: Substrates which attract Spalangia endius (Hymenoptera, Pteromalidae) determined by an olfactometer. Rev. Bras. Entomol. 38: 447-451.

Stafford K.C., Pitts C.W. \& WebB T.L. 1984: Olfactometer studies of host seeking by the parasitoid Spalangia endius Walker (Hymenoptera: Pteromalidae). Environ. Entomol. 13: 228-231.

SteIDLE J.L.M. \& VAn Loon J.J.A. 2003: Dietary specialization and infochemical use in carnivorous arthropods: testing a concept. Entomol. Exp. Appl. 108: 133-148.

Steidle J.L.M., Steppuhn A. \& Ruther J. 2003: Specific foraging kairomones used by a generalist parasitoid. J. Chem Ecol. 29: 131-143.

STEINER S. \& RUTHER J. 2009: How important is sex for females of a haplodiploid species under local mate competition? Behav. Ecol. 20: 570-574.

Sullivan B.T., Pettersson E.M., Seltmann K.C. \& Berisford C.W. 2000: Attraction of the bark beetle parasitoid Roptro- cerus xylophagorum (Hymenoptera: Pteromalidae) to hostassociated olfactory cues. Environ. Entomol. 29: 1138-1151.

Vet L.E.M., De Jong A.G., Franchi E. \& Papaj D.R. 1998: The effect of complete versus incomplete information on odour discrimination in a parasitic wasp. Anim. Behav. 55: 1271-1279.

VölKL W. \& Sullivan D.J. 2000: Foraging behaviour, host plant and host location in the aphid hyperparasitoid Euneura augarus. Entomol. Exp. Appl. 97: 47-56.

Werren J.H., Gadau J., Beukeboom L., Desplan C., Lynch J., Rivers R., Richards S. \& van de Zande L. 2004: Proposal to Sequence the Nasonia Genome. http://www.genome.gov/ Pages/Research/Sequencing/SeqProposals/NasoniaSeq.pdf

Werren J.H., Richards S., Desjardins C.A, Niehuis O., Gadau J., Colbourne J.K. \& The Nasonia Genome Working Group 2010: Functional and evolutionary insights from the genome of three parasitoid Nasonia species. Science 327: 343-348.

Whiting A.R. 1967: The biology of the parasitic wasp Mormoniella vitripennis (Nasonia brevicornis) (Walker). Q. Rev. Biol. 42: 333-406.

WyLIE H.G. 1958: Factors that affect host finding by Nasonia vitripennis (Walk.) (Hymenoptera: Pteromalidae). Can. Entomol. 90: 597-608.

Received April 14, 2011; revised and accepted July 12, 2011 